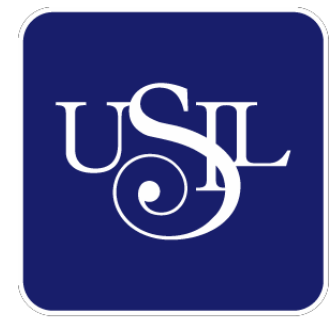

UNIVERSIDAD

SAN IGNACIO

DE LOYOLA

ESCUELA DE POSTGRADO

\title{
PLANEAMIENTO ESTRATÉGICO PARA REPRESENTACIONES MARTIN S.A.C., SEDE PUENTE PIEDRA
}

Trabajo de Investigación para optar el grado de:

DORA ALIS FRANCISCO ROJAS

Maestro en Ciencias Empresariales con Mención en Marketing y Gestión de Comercial

\section{GINA ROXANA LIENDO ARANIBAR}

Maestro en Ciencias Empresariales con Mención en Gestión del Capital Humano

\section{ANA LISSET NAPAN ORTEGA}

Maestro en Ciencias Empresariales con Mención en Gestión

Comercial

\section{Asesor:}

Luis Fernando Peredo Rojas

$$
\text { Lima - Perú }
$$

2019 


\section{“PLANEAMIENTO ESTRATÉGICO PARA REPRESENTACIONES MARTIN S.A.C., SEDE PUENTE PIEDRA"}




\section{Agradecimiento}

Agradecemos a Dios y la Virgen por el desarrollo del presente proyecto así como a nuestros familiares, a nuestro asesor Luis Fernando Peredo Rojas y a las personas que de una u otra manera colaboraron en algún aspecto. 


\section{Resumen Ejecutivo}

El objetivo de la presente tesis es elaborar un plan estratégico para la empresa Representaciones Martin S.A.C., sede Puente Piedra, para el periodo 2018 - 2022 con el objetivo de asegurar el liderazgo y consolidar un crecimiento sostenido.

Representaciones Martin S.A.C. es una empresa de capital totalmente peruano, la cual tiene 21 años en el mercado, inició comercializando triplay, sin embargo, se fue adaptando a las necesidades del mercado, hoy en día, concentra la mayoría de sus ventas y rentabilidad en los tableros de melamina, producto que se utiliza para la elaboración de muebles, asimismo, comercializa los complementos necesarios para abastecer a la industria del mueble, en la actualidad cuenta con 4 sedes ubicadas estratégicamente en distintas partes del país. La sede del presente estudio, sede Puente Piedra, inició sus operaciones en setiembre del 2015. En la actualidad, la sede Puente Piedra tiene el $7 \%$ de la participación de las ventas de la empresa, tomando el primer trimestre del año 2017. Así también, es importante mencionar que no cumplió su objetivo al cierre del año 2016 llegando a obtener el 83\% del objetivo planteado, por lo cual se considera conveniente la elaboración de su propio plan estratégico.

En líneas generales, el documento plantea en un inicio la reformulación de la visión de la empresa considerando las sugerencias académicas que deben trabajarse para su mejor conceptualización. En cuanto a la misión, se sugirió agregar el rubro en el que se encuentra la empresa, así como incluir que dicha misión se llevará a cabo de manera sostenida.

En relación al análisis externo, se concluyó que las oportunidades con mayor peso son que el mercado del diseño de interiores y decoración es cambiante, así como, el crecimiento que existe del uso de los tableros de melamina. Asimismo, dentro de las amenazas con mayor importancia se encontraron el aumento de locales de la competencia en la zona Lima Norte y la ampliación del rubro concerniente a los tableros de melamina de los home centers.

Del análisis interno, se concluye que tiene como fortalezas más importantes el tener como principal proveedor a Tableros Hispanos, marca de tableros de melamina que forma parte del mismo grupo empresarial, que posee el $41 \%$ de participación dentro de la categoría principal de la empresa como son los tableros de melamina y una rentabilidad del 34\%, Así también, una fortaleza importante, es el poseer maquinarias con tecnología de última generación.

Como resultado del análisis de los factores claves de éxito, se determinó, considerando la opinión de expertos en la materia, que la empresa se encuentra por encima del puntaje 
promedio de la evaluación, sin embargo, se detectó que se tiene que poner énfasis en algunas debilidades como son: capacitación del personal de ventas y lograr mayor lealtad con los clientes.

De la matriz de planeación estratégica se obtuvo como resultado que la estrategia más conveniente es penetración de mercado, la cual se llevará a cabo mediante algunas actividades específicas como son: implementar un plan de publicidad, realizar alianzas estratégicas con los principales proveedores y difundir y promocionar la experiencia y ventajas diferenciales. Así también, como estrategia contingente se tendrá: desarrollo de mercado.

El presupuesto para la implementación de la estrategia de penetración de mercado es de S/.997,856.00 el cual sería el $80 \%$ del valor financiado y el $20 \%$ restante asumido por los accionistas.

Se recomienda el desarrollo de este plan estratégico para Representaciones Martin, sede Puente Piedra, ya que permitirá a la empresa mejorar su rentabilidad. Siendo así, la TIRE del $58,6 \%$ y el VANE de s/5, 844,096 que se obtendrá en la evaluación económica, ambos indicadores son mayores a cero, con lo que se demuestra que se obtendrían importantes beneficios y generarían valor a los accionistas al poner en ejecución el plan. 


\section{Índice}

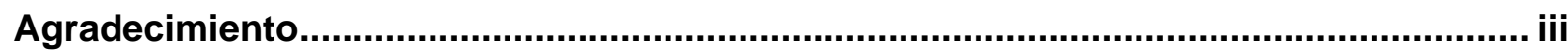

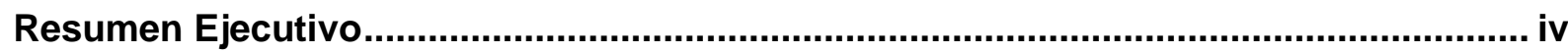

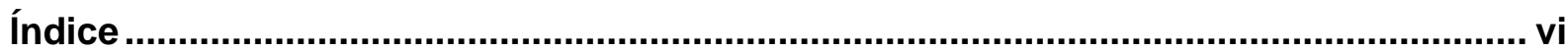

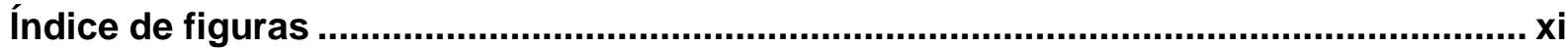

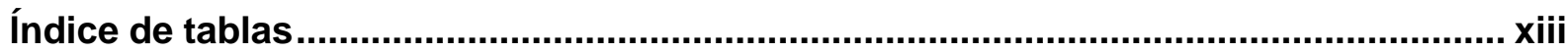

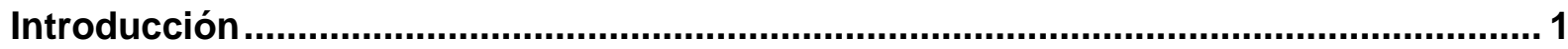

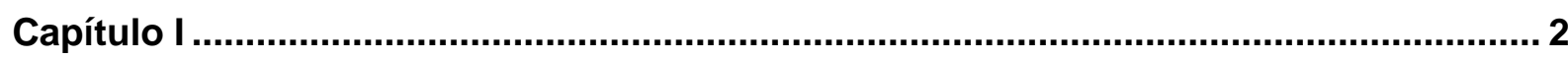

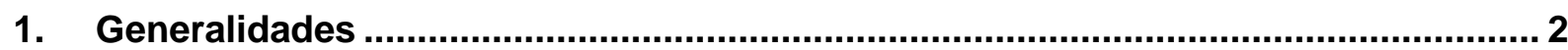

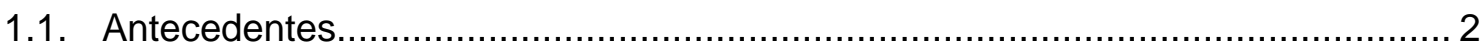

1.2. Determinación del problema u oportunidad .................................................... 4

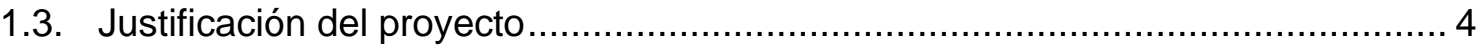

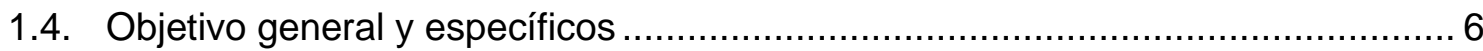

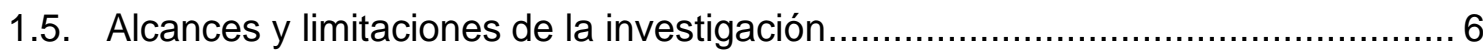

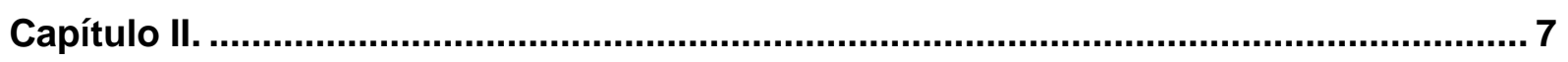

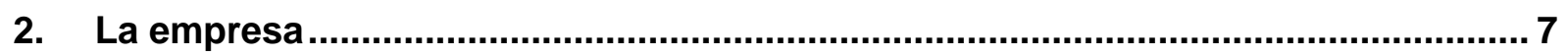

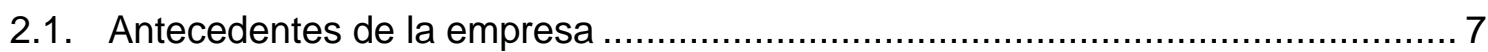

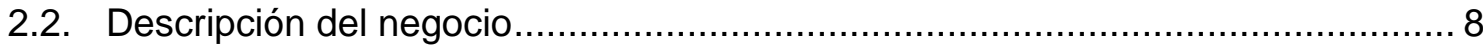

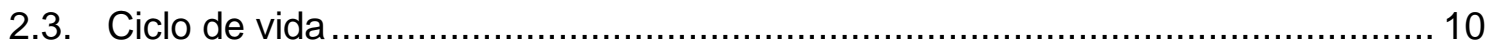

2.3.1. Ciclo de vida de la Industria ............................................................10

2.3.2. Ciclo de vida de la empresa ............................................................11

2.3.3. Ciclo de vida del producto ………………….................................12

2.4. Estructura organizacional actual de la empresa............................................ 19

2.5. Estructura organizacional basada en el focus group aplicado al personal ha

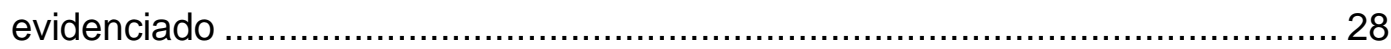




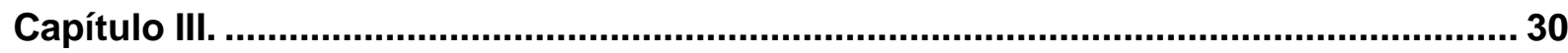

3. Formulación de Visión, misión y valores de la empresa.......................................... 30

3.1. Visión 30

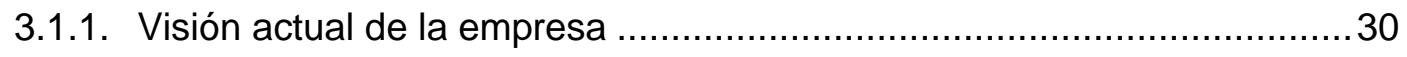

3.1.2. Análisis de la visión actual.......................................................... 30

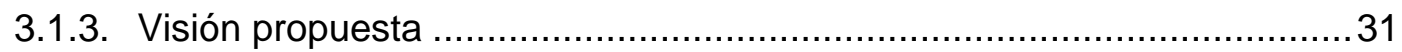

3.2. Misión 32

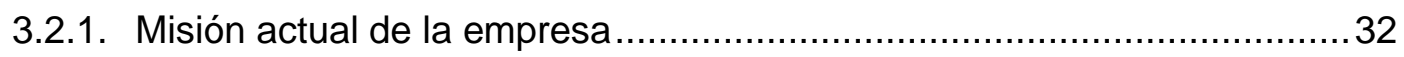

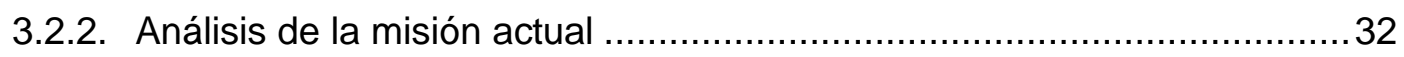

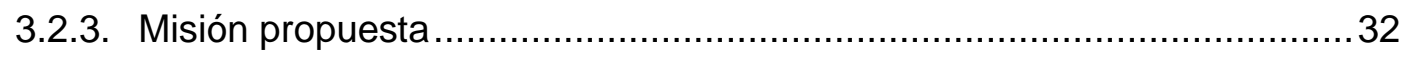

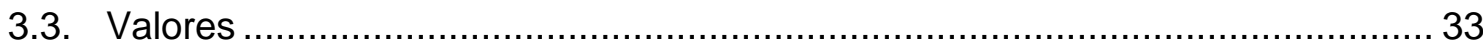

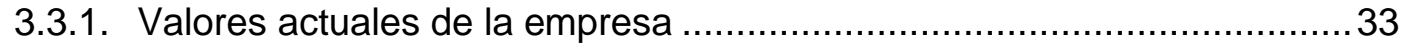

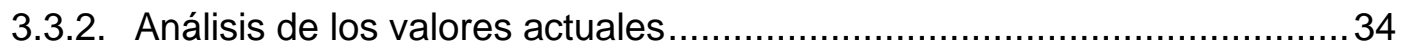

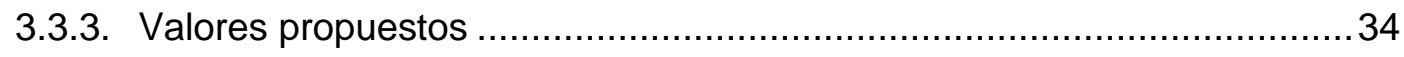

3.4. Alineamiento estratégico de la visión, misión y valores de la empresa ............... 35

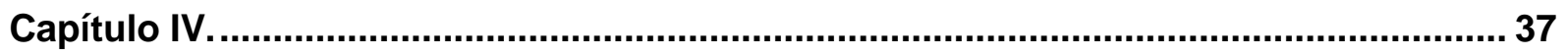

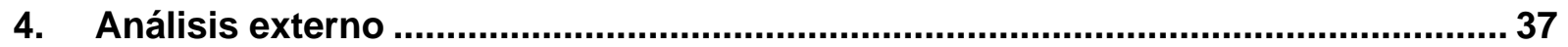

4.1. Tendencias de las variables del macro entorno de la industria ....................... 37

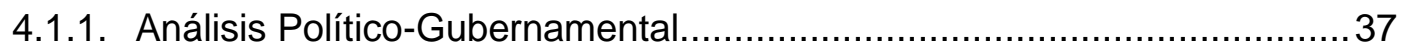

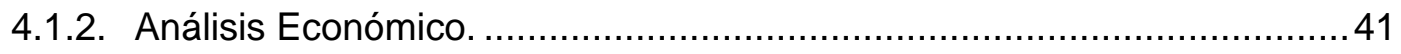

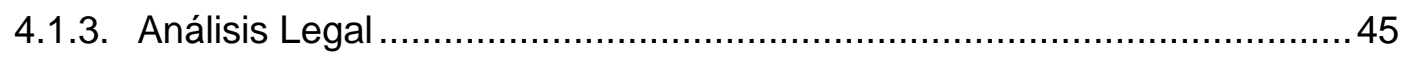

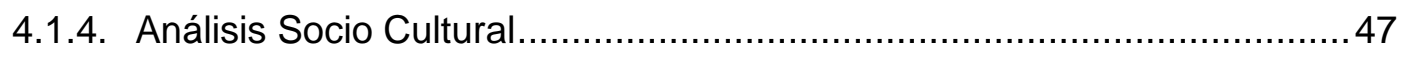

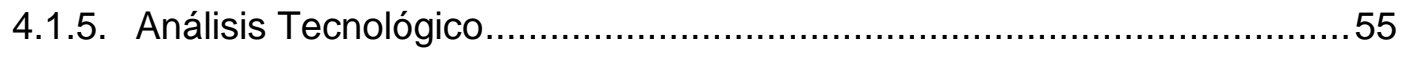

4.1.6. Análisis de Impacto Ambiental ....................................................58

4.2. Impacto de cada una de las variables del entorno en clientes / proveedores ..... 59

4.3. Impacto de cada una de las variables en la empresa ................................. 62

4.4. Matriz de Evaluación de los Factores Externos (EFE) .............................. 65 


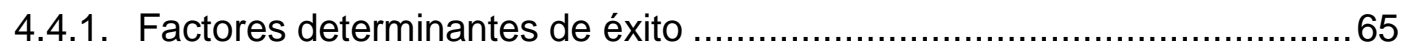

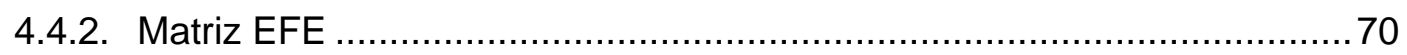

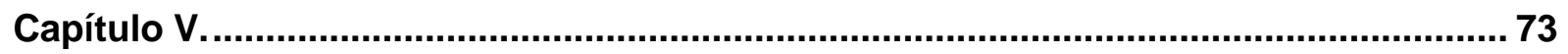

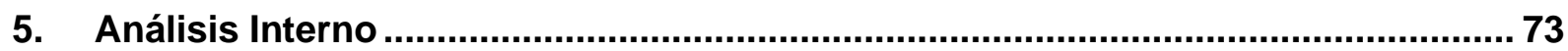

5.1. Descripción de la cadena de valor de la empresa........................................... 73

5.2. Indicadores de cada una de las actividades de la cadena de valor ....................80

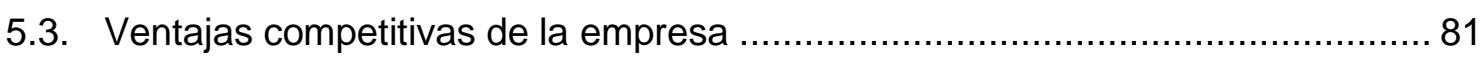

5.4. Matriz de la evaluación de los factores internos (EFI) ...................................... 83

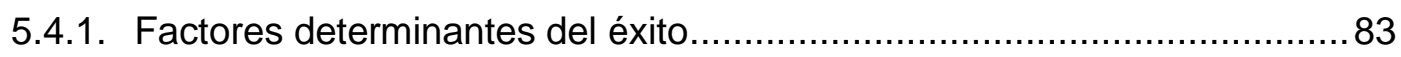

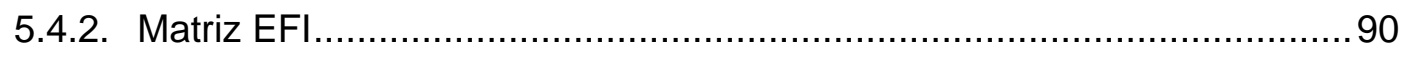

Capítulo VI.

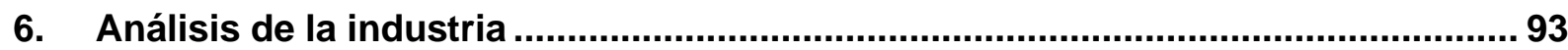

6.1. Descripción del Mercado (demanda) e Industria (oferta) …….......................... 93

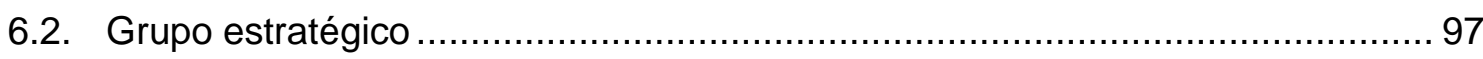

6.3. Descripción las cinco fuerzas competitivas de la industria .................................98

6.3.1. Poder de negociación de los clientes ..................................................99

6.3.2. Poder de negociación de los proveedores.......................................... 100

6.3.3. Amenaza de productos sustitutos.......................................................102

6.3.4. Amenaza de nuevos competidores potenciales................................... 104

6.3.5. Rivalidad entre los competidores......................................................... 107

6.4. Matriz de atractividad de cada una de las cinco fuerzas ................................ 108

6.5. Análisis del Grado de atractividad de la industria......................................... 112

6.6. Matriz de Perfil Competitivo MPC ……....................................................... 113

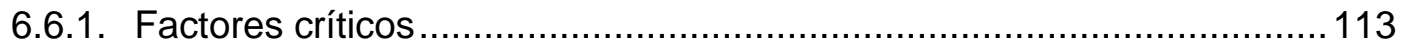

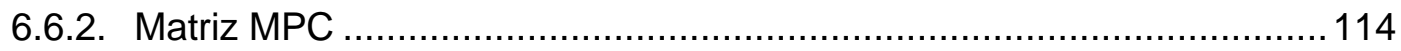

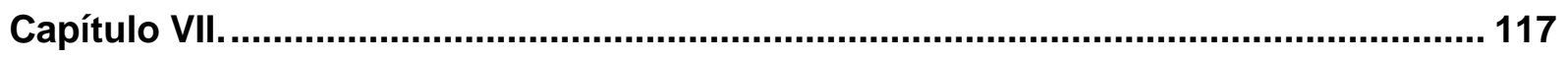

7. Formulación de los objetivos y diseño de las estrategias .................................... 117 


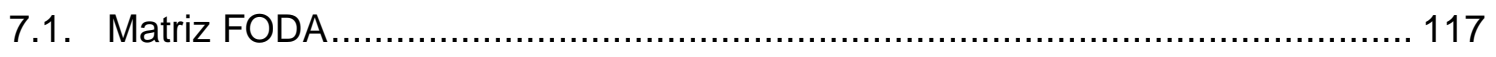

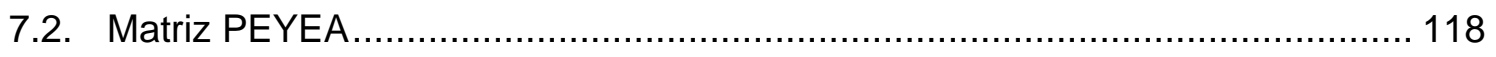

7.3. Matriz Boston Consulting Group ............................................................... 122

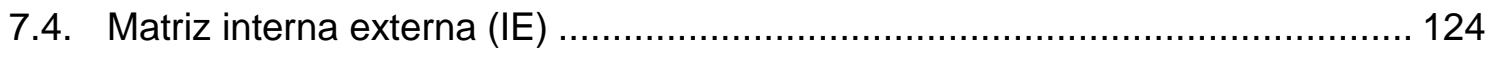

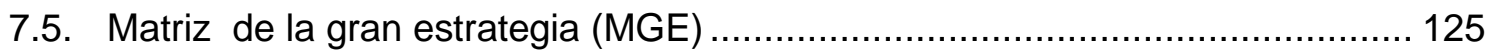

7.6. Matriz de planificación ampliada .............................................................. 126

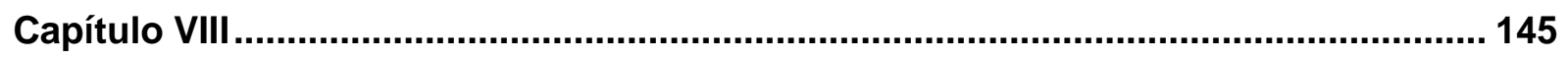

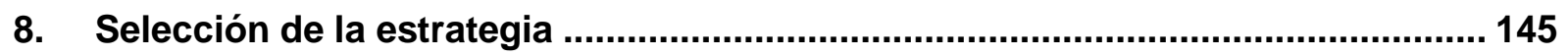

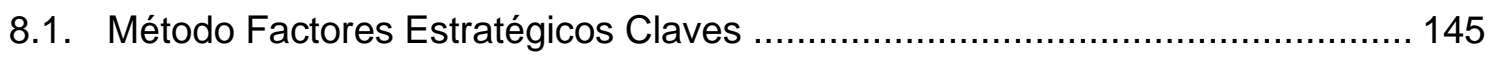

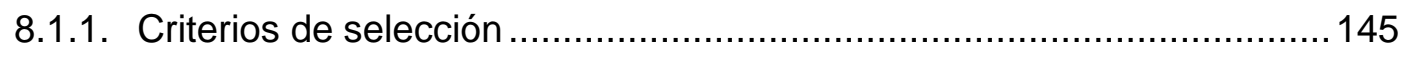

8.2. Matriz de Planeación Estratégica Cuantitativa MPEC ...................................... 146

8.3. Descripción de estrategia seleccionada....................................................... 148

8.4. Descripción de estrategia contingente …………….................................. 148

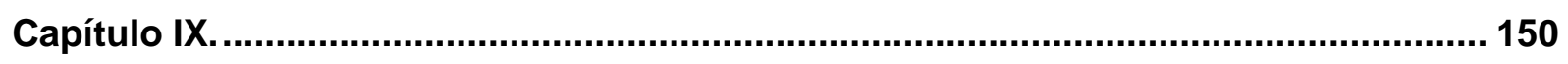

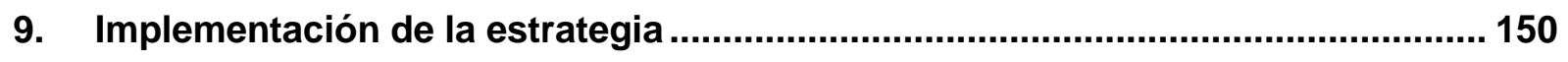

9.1. Descripción de la nueva estructura organizacional de la empresa................... 150

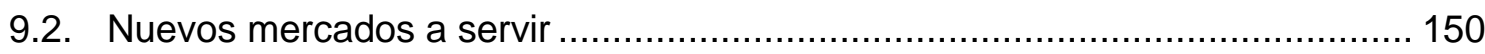

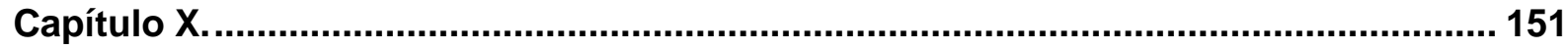

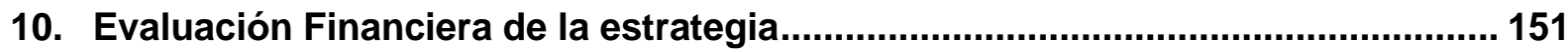

10.1. Proyección de estados financieros (situación actual y situación con la nueva

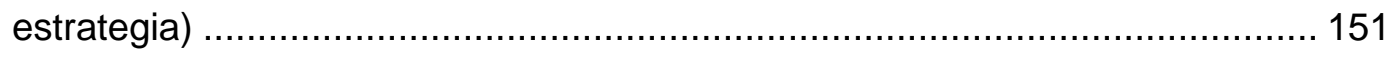

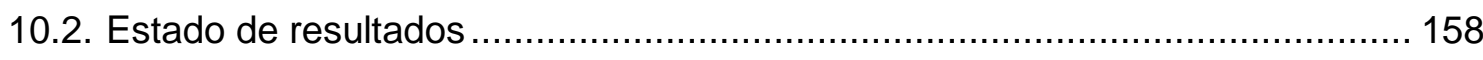

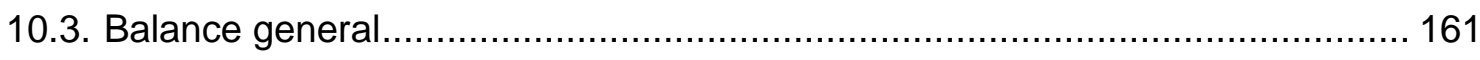

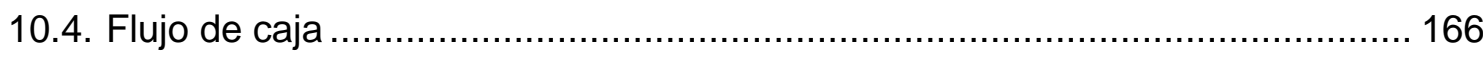

10.5. Evaluación financiera (VAN, TIR y ratios financieros) …................................ 168

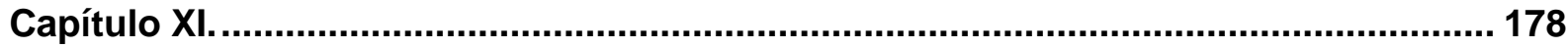

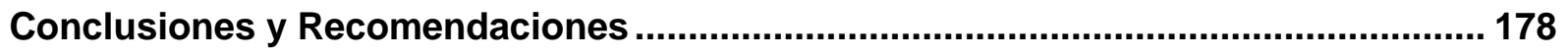




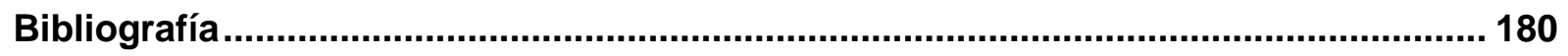

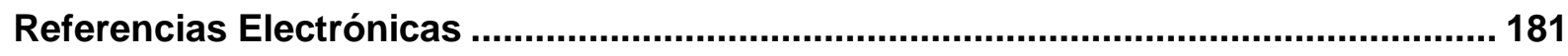

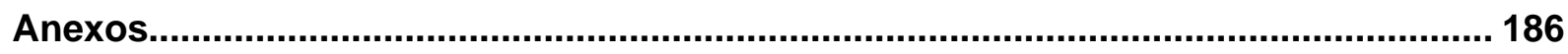

Anexo 1. Importaciones totales de Perú según partida arancelaria.......................... 187

Anexo 2. Importaciones de Perú - Año 2016 ..................................................... 188

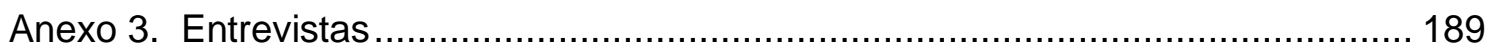

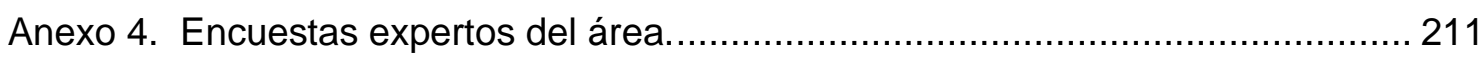

Anexo 5. Relación de fortalezas, debilidades, amenazas y oportunidades de la empresa Representaciones Martin. ........................................................... 231

Anexo 6. Encuesta realizada para determinar los pesos y calificaciones de los factores

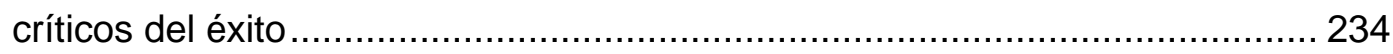

Anexo 7. Imágenes de diferentes tableros de madera.......................................... 240 


\section{Índice de figuras}

Figura 1. Participación de ventas de las sede de las Tiendas Representaciones 5

Figura 2. Evolución de la Empresa Representaciones Martin S.A.C.

Figura 3. Líneas de productos de Representaciones Martin S.A.C 8

$\begin{array}{ll}\text { Figura 4. Participación de las líneas de productos en las ventas } & 9\end{array}$

Figura 5. Representaciones Martin S.A.C. evolución de ventas (Soles) 14

Figura 6. Evolución de la Utilidad Neta de Tableros de Melamina 15

$\begin{array}{lr}\text { Figura 7. Ciclo del producto Tableros de Melamina. } & 16\end{array}$

$\begin{array}{ll}\text { Figura 8. Organigrama del área Administrativa } & 20\end{array}$

$\begin{array}{ll}\text { Figura 9. Organigrama del área Administrativa } & 20\end{array}$

$\begin{array}{ll}\text { Figura 10. Organigrama del área Administrativa } & 21\end{array}$

Figura 11. Alineamiento Estratégico de la visión, misión y valores 36

Figura 12. Tasa de Crecimiento $2006-2017$.

Figura 13. Daños en Viviendas (miles de unidades). 39

Figura 14. Crecimiento de números de Tiendas de Home Centers 41

Figura 15. Producto Bruto Interno y Demanda Interna 2008 al 2017

Figura 16. Proyeccion de la inflación, 2015-2019 43

Figura 17. Porcentaje de personas según nivel socioeconómico 2017.

Figura 18. Porcentaje de lealtad a los clientes. 50

Figura 19. Top 5 en generación de empleo, por rama industrial 52

Figura 20. Informalidad según sector productivo 2015

Figura 21. IPSOS, 2016. Perú 2017, de la informalidad a la modernidad. 54

$\begin{array}{ll}\text { Figura 22.¿Por qué adquieren las empresas un nuevo ERP? } & 57\end{array}$

Figura 23. Cadena de Valor de la empresa Representaciones Martin. 74 
Figura 24. Logística interna de la empresa

Figura 25. Logística externa de la empresa

Figura 26. Flujo generación de pedido.

80

Figura 27. Empresas innovativas de la industria manufacturera

Figura 28. Matriz PEYEA

122

Figura 29. Matriz BCG

123

Figura 30. Matriz interna y externa

125

Figura 31. Matriz de la Gran Estrategia.

126 


\section{Índice de tablas}

Tabla 1 Utilidad promedio de las marcas de tablero de melamina

Tabla 2 Número de contenedores vendidos durante el 1er semestre del 2017 según marca 10

Tabla 3 Ventas anuales en soles de la empresa Representaciones Martin S.A.C. 12

Tabla 4 Características, objetivos y estrategias del ciclo de vida de los productos 13

Tabla 5 Evolución de ventas soles de tableros de melamina 2014 -2016 14

Tabla 6 Evolución de la utilidad neta (soles) de tableros de melamina 2014-2016. 15

Tabla 7 Tableros de melamina, evolución de las ventas y utilidad neta 16

Tabla 8 Variación porcentual de las importaciones de tableros de aglomerados/ 18

$\begin{array}{lr}\text { Tabla } 9 \text { Número de personal por área de la empresa } & 19\end{array}$

Tabla 10 Matriz de la visión propuesta para la empresa 32

Tabla 11 Alineamiento estratégico visión, misión y valores 36

Tabla 12 Variación porcentual a Junio del 2017 del tipo de cambio. 44

Tabla 13 Aspectos más relevantes al decidir la compra e muebles 48

Tabla 14 Distribución de niveles por zona APEIM 2017-Lima Metropolitana 49

$\begin{array}{ll}\text { Tabla } 15 \text { Variables del entorno e impacto en cliente/proveedor } & 61\end{array}$

Tabla 16 Variables del entorno e impacto en la empresa 64

$\begin{array}{ll}\text { Tabla } 17 \text { Resumen de oportunidades } & 65\end{array}$

$\begin{array}{ll}\text { Tabla } 18 \text { Resumen de amenazas } & 67\end{array}$

Tabla 19 Matriz de evaluación de Factores externos (EFE) 71

$\begin{array}{ll}\text { Tabla } 20 \text { Indicadores de la cadena de valor } & 81\end{array}$

$\begin{array}{lc}\text { Tabla } 21 \text { Matriz VRIO } & 83\end{array}$

Tabla 22 Principales maquinarias usadas en la tienda. $\quad 86$

$\begin{array}{lr}\text { Tabla } 23 \text { Resumen de fortalezas } & 89\end{array}$ 
Tabla 24 Resumen de debilidades

Tabla 25 Matriz de evaluación de Factores internos (EFI) 91

Tabla 26 Variación de las importaciones de Aglomerado/MDP por Importador 94

Tabla 27 Perú importación de productos forestales maderables por productos, año 201595

Tabla 28 Variación porcentual de la producción en el Subsector Manufacturero no primario 96

$\begin{array}{lr}\text { Tabla } 29 \text { Análisis del poder de los clientes } & 109\end{array}$

Tabla 30 Análisis del poder de los proveedores 110

$\begin{array}{ll}\text { Tabla } 31 \text { Análisis de los sustitutos } & 110\end{array}$

Tabla 32 Análisis de las barreras de entrada y salida 111

Tabla 33 Análisis de la rivalidad entre competidores 112

$\begin{array}{ll}\text { Tabla } 34 \text { Análisis del grado de atractividad } & 113\end{array}$

Tabla 35 Matriz de perfil competitivo $\quad 115$

$\begin{array}{ll}\text { Tabla } 36 \text { Matriz FODA } & 117\end{array}$

Tabla 37 Posición estratégica interna y externa 120

Tabla 38 Participación del mercado de la empresa 123

$\begin{array}{ll}\text { Tabla } 39 \text { Matriz amplificada área Logística } & 127\end{array}$

Tabla 40 Matriz amplificada área Recursos Humanos 129

Tabla 41 Matriz amplificada área Financiero 133

$\begin{array}{ll}\text { Tabla } 42 \text { Matriz amplificada área Comercial } & 137\end{array}$

Tabla 43 Matriz de decisión estratégica 145

Tabla 44 Matriz de planeación estratégica competitiva 146

Tabla 45 Proyección de ventas en la situación actual 151

Tabla 46 Relación de costos y precios de venta de los tableros 152

Tabla 47 Volúmenes de ventas 152

Tabla 48 Pagos por obligaciones 153 
Tabla 49 Depreciación

Tabla 50 Depreciación

Tabla 51 Proyección de ventas soles separando la línea principal de las otras ventas

Tabla 52 Crecimiento de ventas soles en la situación con la estrategia

Tabla 53 Presupuesto de Compras

Tabla 54 Proyección de los Estados de Resultados sin estrategia

Tabla 55 Presupuesto de Gastos Administrativos

Tabla 56 Presupuesto de Gastos de Ventas

Tabla 57 Presupuesto de Gastos Financieros

Tabla 58 Proyección de los Estados de Resultados con la nueva estrategia

Tabla 59 Balance General en una situación actual

Tabla 60 Condiciones del financiamiento bancario

Tabla 61 Resumen de financiamiento bancario

Tabla 62 Cronograma de financiamiento bancario

Tabla 63 Balance General en una situación con la nueva estrategia

Tabla 64 Proyección de los Flujos de cajas sin estrategia

Tabla 65 Proyección de los Flujos de cajas con estrategia

Tabla 66 Detalle de la inversión

Tabla 67 Monto a invertir en el proyecto

Tabla 68 Determinación del COK Nominal EEUU

Tabla 69 Determinación del COK Real EEUU

Tabla 70 Determinación del beta del sector

Tabla 71 Determinación del COK Real Perú

Tabla 72 Determinación del costo de la deuda

Tabla 73 Determinación del patrimonio inversionista (WACC) 
Tabla 74 Cálculo del Valor actual neto (VAN) y la Tasa Interna de retorno (TIR)

Tabla 75 Ratios de liquidez

Tabla 76 Ratios de gestión

Tabla 77 Ratios de endeudamiento

Tabla 78 Ratios de rentabilidad 


\section{Introducción}

El presente trabajo desarrolla el Planeamiento Estratégico para la empresa Representaciones Martin S.A.C. sede Puente Piedra para un horizonte de 5 años (2018 -2022). Se realizó un análisis del sector de comercialización de insumos para la elaboración de muebles, sobre todo de la línea principal, tableros de melamina, así como también un análisis sobre la empresa con el propósito principal de identificar la estrategia más adecuada para lograr los objetivos planteados.

El planeamiento estratégico está dividido en 10 capítulos, los cuales se describen a continuación.

En el capítulo I se muestran las generalidades de la empresa, así como los antecedentes, la justificación, los objetivos, alcances y limitaciones de la investigación. En el capítulo II, se describe los antecedentes de la empresa, la descripción del negocio y el ciclo de vida de la industria, empresa y producto. También se describe la estructura organizacional de la empresa. En el capítulo III, se analizan la visión, misión y valores actuales de la empresa, así como se proponen mejoras para cada uno de estos aspectos. En el capítulo IV, se realiza el análisis de las variables del entorno. En el capítulo $\mathrm{V}$, se realiza el análisis interno de la empresa. En el capítulo VI, se realiza el análisis de la industria. En el capítulo VII, se realiza la formulación de los objetivos y diseño de las estrategias. En el capítulo VIII, se determina la selección de la estrategia. En el capítulo IX, se describe la implementación de la estrategia seleccionada. En el capítulo $\mathrm{X}$, se realiza la evaluación financiera de la estrategia. 